\title{
Visual impairment and refractive error amongst school-going children aged 6-18 years in Sekhukhune District (Limpopo, South Africa)
}

\begin{tabular}{|c|c|}
\hline \multicolumn{2}{|c|}{$\begin{array}{l}\text { Authors: } \\
\text { Tshubelela S.S. Magakwe } \\
\text { Zamadonda N.Q. } \\
\text { Xulu-Kasaba }{ }^{1} \text { (1) } \\
\text { Rekha Hansraj }^{1} \text { (D) }\end{array}$} \\
\hline \multicolumn{2}{|c|}{$\begin{array}{l}\text { Affiliation: } \\
{ }^{1} \text { Department of Optometry, } \\
\text { Faculty of Health Sciences, } \\
\text { University of KwaZulu-Natal, } \\
\text { Durban, South Africa }\end{array}$} \\
\hline \multicolumn{2}{|c|}{$\begin{array}{l}\text { Corresponding author: } \\
\text { Zamadonda Xulu-Kasaba, } \\
\text { XuluKasabaZ@ukzn.ac.za }\end{array}$} \\
\hline \multicolumn{2}{|c|}{$\begin{array}{l}\text { Dates: } \\
\text { Received: } 07 \text { Jan. } 2020 \\
\text { Accepted: } 25 \text { July } 2020 \\
\text { Published: } 05 \text { Oct. } 2020\end{array}$} \\
\hline \multicolumn{2}{|c|}{$\begin{array}{l}\text { How to cite this article: } \\
\text { Magakwe TSS, Xulu-Kasaba } \\
\text { ZNQ, Hansraj R. Prevalence } \\
\text { and distribution of visual } \\
\text { impairment and refractive } \\
\text { error amongst school-going } \\
\text { children aged 6-18 years in } \\
\text { Sekhukhune District } \\
\text { (Limpopo, South Africa). } \\
\text { Afr Vision Eye Health. } \\
\text { 2020;79(1), a551. https://doi. } \\
\text { org/10.4102/aveh.v79i1.551 }\end{array}$} \\
\hline \multicolumn{2}{|c|}{$\begin{array}{l}\text { Copyright: } \\
\text { (c) 2020. The Author(s). } \\
\text { Licensee: AOSIS. This wo } \\
\text { is licensed under the } \\
\text { Creative Commons } \\
\text { Attribution License. }\end{array}$} \\
\hline \multicolumn{2}{|l|}{ Read online: } \\
\hline 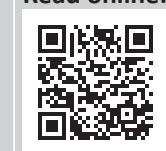 & $\begin{array}{l}\text { Scan this QR } \\
\text { code with your } \\
\text { smart phone or } \\
\text { mobile device } \\
\text { to read online. }\end{array}$ \\
\hline
\end{tabular}

Background: Refractive error (RE) and visual impairment (VI) remain major problems affecting school-going children worldwide.

Aim: To determine the prevalence and distribution of VI and RE in school-going children aged 6-18 years.

Setting: The study was conducted in Sekhukhune District, Limpopo, South Africa.

Methods: A multistage random sampling method was used to select school-going children aged 6-18 years from Grades 1 to 12 . A total of 326 learners went through eye examinations, which included visual acuity (VA) measurement using a logarithm of the minimum angle of resolution chart, autorefraction under cycloplegia and ocular health assessment.

Results: The prevalence of uncorrected, presenting and best-corrected VA of $0.30 \mathrm{M}$ or worse in the better eye was $12.3 \%$ (95\% confidence interval [CI], 8.70-15.80), 12.3\% (95\% CI, 8.70-15.80) and $2.1 \%$ (95\% CI, 0.60-3.70), respectively. Refractive error accounted for $80 \%$ (95\% CI, 67.6-92.4) of all causes of VI. Myopia was the most prevalent RE (50.7\%; 95\% CI, 38.8-62.7), followed by astigmatism (36\%; 95\% CI, 24.3-47.3) and hypermetropia (13.6\%; 95\% CI, 5.30-21.6). There was no significant difference in the prevalence of RE and VI between males (50.7\%; 95\% CI, 38.8-62.7) and females (49.3\%; 95\% CI, 37.3-61.2). Refractive error and VI were higher amongst children aged 14-18 years: $56.7 \%$ (95\% CI, 44.9-68.6) and 60\% (95\% CI, 44.8-75.20), respectively.

Conclusion: The prevalence of RE and VI amongst school-going children in Sekhukhune District was high, highlighting the need for school visual screening and strategies to address these conditions in that area.

Keywords: refractive error, visual impairment, myopia, hypermetropia, school-going children, learner eye health

\section{Introduction}

The World Health Organisation (WHO) has made a call to all nations to prioritise the management of refractive error (RE) and visual impairment (VI) as they are the second leading cause of avoidable blindness globally. ${ }^{1}$ Refractive error is a visual disorder caused by irregularity in the shape and/or size of the eye, resulting in difficulty when attempting to focus objects clearly leading to blurred vision. ${ }^{2}$ Linked to RE is VI, which results when the RE cannot be corrected by conventional spectacles, contact lenses, surgery or medical intervention. ${ }^{3}$ In addition, in some instances, RE remains uncorrected for a variety of other reasons including inaccessibility and unaffordability, which further contributes to the statistics on VI. Uncorrected refractive error (URE) and VI remain a major problem affecting school-going children worldwide, and this has broader social and economic negative impacts. ${ }^{4}$

Refractive errors, particularly myopia, pose a serious challenge on the individual and society. Hashemi Hassan et al..$^{5}$ recently indicated that globally, $11.7 \%$ of children are myopic, whilst a further $4.6 \%$ and $4.9 \%$ have hypermetropia and astigmatism, respectively. ${ }^{5}$ Moreover, the prevalence of RE differs from region to region, with the highest prevalence in the Asian populations, where China has a prevalence of $20.6 \%,{ }^{6}$ followed by India with $10.2 \%,{ }^{7}$ Saudi Arabia with $18.6 \%{ }^{8}$ and Vietnam with $19.4 \% .{ }^{9}$ Several studies conducted in Chile, the United States and Cambodia reveal RE prevalence values of $18.79 \%,{ }^{10} 13.1 \%{ }^{11}$ and $6.5 \%,{ }^{12}$ respectively. In Africa, Ghana had an RE prevalence value of $3.7 \%,{ }^{13}$ Nigeria $11.5 \%,{ }^{14}$ Ethiopia $6.3 \%,{ }^{15}$ Egypt $2.2 \%{ }^{16}$ and South Africa 7.1\%, as shown in Table $1 .{ }^{17}$ The African continent has shown a comparatively low 
prevalence of RE between $2 \%$ and $12 \% .^{13,14,15,16,17}$ However, this does not suggest that there is no prevalence of RE, because the prevalence from all regions of Africa is not readily available. Several studies have indicated that people living in urban areas have a higher prevalence of RE than people living in rural areas..$^{10,12,18,19}$ On the contrary, $\mathrm{Al}$ Wadaani et al. ${ }^{20}$ reported that children coming from rural areas have a higher prevalence of RE compared to their urban counterparts.

The leading type of RE with a serious impact on the lives of children was found to be myopia.5,16,17,21,22 Myopia was also associated with different prevalences with respect to gender, ${ }^{14,15,18}$ age ${ }^{15,23,24}$ and parents' level of education. ${ }^{25,26,27}$ The higher prevalence of myopia in children in recent years has been attributed to urbanisation and subsequently from increased indoor activities, watching television and playing computer games..$^{10,12,28}$ Myopia was also found associated with older children, while hyperopia was associated with the younger age group..$^{23,25,26}$ Although in South Africa, Wajuihian et al. ${ }^{17}$ did not find any evidence of an association between RE, gender and age, elsewhere myopia has been associated with gender, in some cases with a higher prevalence in girls than boys ${ }^{14,15,29}$ and in others a higher prevalence in boys than girls..$^{30,31,32}$ As it is known that parents' level of education is also associated with myopia, children of people with post-matric qualifications have been found to be more myopic than children whose parents only have a high school qualification or lower. ${ }^{26,27}$

Refractive error is also associated with VI if it remains uncorrected. ${ }^{33,34}$ Global statistics reveal that there are about 19 million visually impaired children in the world, most residing within the African continent, and with URE as the leading cause of their VI. ${ }^{35}$ A study done by Pascolini and Mariotti ${ }^{35}$ indicated that the global prevalence of VI amongst children is 18.9 million (6.6\%). Moreover, the prevalence of VI also differs from region to region, with sub-Saharan Africa being at the top of the list. ${ }^{35}$ The reported prevalence of VI amongst schoolchildren is $12.77 \%$ in Chile, ${ }^{6} 1.9 \%$ in Southern Asia, ${ }^{21} 12.2 \%$ in Vietnam, ${ }^{24} 21.6 \%$ in Pakistan, ${ }^{31} 7.7 \%$ in China, ${ }^{33} 6.22 \%$ in India, ${ }^{36} 1.8 \%$ in Ethiopia, ${ }^{37} 3.66 \%$ in Ghana ${ }^{38}$ and $2.74 \%$ in South Africa. ${ }^{24}$

The African continent has the highest prevalence of VI in children after Asia; ${ }^{35}$ however, there is insufficient data available in South Africa in this respect. ${ }^{39}$ More studies are needed to determine the current prevalence of RE and VI on school going children inclusive of all age groups that could guide intervention strategies in dealing with this global issue. ${ }^{37}$ The aim of this study therefore was to determine the prevalence and distribution of RE and VI amongst schoolgoing children aged 6-18 years in the greater Sekhukhune District in Limpopo Province, South Africa.

\section{Methods}

A quantitative, cross-sectional, school-based study was conducted. Participants underwent vision testing at their respective schools in Sekhukhune District, which is one of the five districts in Limpopo Province, the northernmost province of South Africa. It is the smallest district of the Limpopo Province, making up 11\% of the geographical area (i.e. $13528 \mathrm{~km}^{2}$ ) with a population of 1169762 (Final IDP/ Budget Review, 2017-2018 by the Executive Mayor KS Ramaila, 2018). ${ }^{46}$ Greater Sekhukhune District is further divided into four local municipalities.

The study population comprised school-going children aged 6-18 years in the chosen district and residing in the rural area of Makhuduthamaga municipality which was selected by convenience sampling. This municipality is representative of greater Sekhukhune District. In 2016, 105023 children were enrolled at various schools in Makhuduthamaga. ${ }^{47}$

A sample size of 337 was decided upon in consultation with a statistician. Multistage random sampling was used to select the participants. A total of 400 learners from

TABLE 1: Prevalence of refractive errors in African countries.

\begin{tabular}{|c|c|c|c|c|c|c|c|c|c|}
\hline Author & Country/region & Year & Age (years) & Sample size & $\begin{array}{l}\text { Prevalence } \\
\text { of } \operatorname{RE}(\%)\end{array}$ & $\begin{array}{l}\text { Prevalence of } \\
\text { myopia (\%) }\end{array}$ & $\begin{array}{c}\text { Prevalence of } \\
\text { hypermetropia }(\%)\end{array}$ & $\begin{array}{c}\text { Prevalence of } \\
\text { astigmatism (\%) }\end{array}$ & Ethnicity \\
\hline This study & South Africa/Limpopo & 2019 & $6-18$ & 326 & 12.3 & 10.4 & 2.8 & 7.4 & Black/African \\
\hline Wajuihian et al. & South Africa/KwaZulu-Natal & 2017 & $13-18$ & 1586 & 7.1 & 7.0 & 5.0 & 3.0 & Black/African \\
\hline Koomson et al. & Ghana/Ashanti & 2013 & $12-15$ & 2435 & 3.7 & 3.2 & 0.3 & 9.8 & Black/African \\
\hline Ovenseri et al. & Ghana/Cape Coast & 2010 & $5-19$ & 1103 & 25.6 & 6.9 & 4.6 & 14.1 & Black/African \\
\hline Ngozika et al. & Nigeria/Anambra State & 2018 & $5-15$ & 998 & 9.7 & 4.5 & 1.7 & 3.5 & Black/African \\
\hline Wedner et al. & Tanzania/Mwanza & 2000 & $7-19$ & 1386 & 0.7 & 0.1 & 0.5 & 0.1 & Black/African \\
\hline Muma et al. & Kenya/Makueni District & 2009 & $12-15$ & 1439 & 5.2 & 1.7 & 3.2 & 0.3 & Black/African \\
\hline Msiska et al. & Malawi/Ntcheu & 2009 & $12-15$ & 1276 & 2.4 & 1.4 & 0.8 & 0.1 & Black/African \\
\hline Kedir et al. & Ethiopia/Goro District Gurage & 2014 & $7-15$ & 570 & 3.5 & 2.6 & 0.9 & NR & Afro-Asian \\
\hline Mehari et al. & Ethiopia/Woreda Subdistrict & 2013 & $7-18$ & 4238 & 6.3 & 6.0 & 0.33 & 0.76 & Afro-Asian \\
\hline Margirita et al. & Equatorial Guinea/Malabo & 2015 & $6-16$ & 425 & 13.5 & 10.4 & 3.1 & 11.8 & Black/African \\
\hline Gamal et al. & Egypt/South Sinai & 2015 & $6-15$ & 2070 & 29.4 & NR & NR & NR & Arabic \\
\hline
\end{tabular}

Source: Please see the full reference list of the article Ekpenyong BN, Naidoo K, Ahaiwe K, et al. Visual status and prevalence of eye disorders among school-age children in southern Nigeria. African Vis Eye Heal [serial online]. 2017 Jan 30 [cited 2018 Jun 19];76(1):1-6. Available from: http://www.avehjournal.org/index.php/aveh/article/view/377, for more information

$\mathrm{RE}$, refractive error; NR, not reported. 
10 randomly selected schools were invited to participate in this study. Of this number, 24 learners were absent on the day scheduled for examination, 42 learners did not assent to the instilling of topical anaesthetic (Novesin Wander, 1 drop) and cycloplegic eye drops (1\% cyclopentolate, 2-3 drops), and 8 children did not return signed consent forms. Therefore, a total of 326 learners were eventually included in this study. Five grades were randomly selected from each school from Grades 1 to 12. In each grade, the class register was used as a sampling frame to randomly select eight participants, which included an equal number of male and female participants. All selected learners were given information documents and child assent forms detailing the purpose and nature of the study, as well as parental consent forms for their parents to read and sign, confirming consent.

Learners aged 6-18 years who returned signed parental consent forms, signed assent forms and were present at the school on the day of examination were included in this study. Those with any systemic or ocular diseases, as well as those on any systemic or ocular medication, were excluded from this study.

Permission was granted by the principals of the selected schools. This study adhered to the tenets of the Declaration of Helsinki. A training and standardisation workshop was held for all study personnel prior to the commencement of the study. A pilot study was conducted in Elias Motsoaledi Municipality (Groblersdal Academy) to validate the data collection procedures and recording forms. The subjects recruited for the pilot study were excluded from the main study.

\section{Clinical assessment}

A modified Refractive Error Study in Children (RESC) protocol was employed to determine the prevalence values for RE and VI. Visual acuity (VA) was scored with reference to the logarithm of the minimum angle of resolution (LogMAR); each letter was scored independently, and there was no crowding effect as compared to the Snellen chart, which is scored per line. ${ }^{48}$ Distance VA was measured with a retro-illuminated LogMAR chart using the tumbling $\mathrm{E}$ optotype from a distance of $4 \mathrm{~m}$.

Habitual binocular alignment was assessed using the Hirschberg and cover tests in conjunction with a prism bar. Pupillary dilation and cycloplegia (in both eyes) were attained using two drops of $1 \%$ cyclopentolate, after ocular surface anaesthesia, administered $5 \mathrm{~min}$ apart to each eye. If a pupillary light reflex was still present after $15 \mathrm{~min}$, a third drop was administered as required. Cycloplegia was considered complete if the pupillary light reflex was absent and the pupil diameter was $6 \mathrm{~mm}$ or more. The achievement of cycloplegia was necessary irrespective of the extent of dilation.

Refractive findings were achieved with an autorefractor (Topcon RM-8000B). A minimum of five readings with valid confidence rankings as per the manufacturer's instructions were obtained for each eye. The RESC protocol defines myopia in one or both eyes of at least -0.50 dioptre (D), hypermetropia at least $2.00 \mathrm{D}$ in one or both eyes and astigmatism at 0.75 cylindrical refraction or more. The cycloplegic autorefractor findings were inserted in a trial frame for any significant RE as defined above and the aided VA measured as per the procedure described above for VA for all children who attained an initial unaided or aided VA measure of worse than $\operatorname{LogMAR}=0(20 / 20)$. In those cases where the aided VA was worse than $\log M A R=0.30(20 / 40)$, the child was categorised as having VI.

Examination of the anterior segment, lens, vitreous and fundus was performed using a Welch Allyn direct ophthalmoscope. The recording of abnormal findings was important as documentary evidence to support the assignment of a principal cause of impairment. Any abnormal fundus findings were recorded by either fundus drawings or photography. Learners who were found to have URE and/or pathology were referred to eye centres of their choice for further management.

\section{Data management and analysis}

Collected data were captured and analysed using the Statistical Package for Social Sciences (SPSS version 25) in consultation with a statistician. Descriptive statistics including frequency, mean and standard deviation were computed. Data backup was done daily, and the backup copies were stored in a password-protected file. The distribution of the uncorrected, presenting and bestcorrected VA was reported by VA categories. Values of at least $-0.50 \mathrm{D}, 2.00 \mathrm{D}$ and $-0.75 \mathrm{D}$ cylindrical power and above for myopia, hyperopia and astigmatism, respectively, were considered significant. The distribution of spherical equivalent RE amongst those with VI was tabulated by age and gender. The association of myopia or hyperopia with the age and gender of the child was explored with multiple logistic regression. Principle causes of VI (VA, 0.30 LogMAR or worse) were summarised.

\section{Ethical considerations}

Ethical approval was obtained from the Biomedical Research and Ethics Committee (BREC) at the University of KwaZulu-Natal. The Biomedical Research and Ethics Committee is registered with the South African National Health Research Ethics Council (REC-290408-009), ethical clearance number BE080/19, 13 March 2019.

\section{Results Demographics}

A total of 326 learners participated in this study, with an almost equal distribution of gender, as there were 165 (50.6\%) female participants and 161 (49.4\%) male participants. The ages of the learners ranged from 6 to 18 years with a mean of $13.02 \pm 3.9$ years with a comparable 
median age of 13.00 years. The age group mostly represented was $14-18$ years $(47.5 \%)$, and the age group least represented was $6-8$ years $(23.9 \%)$ as indicated in Table 2.

There was a significant difference in the mean age of learners within grades $(p=0.00)$. In general, the highest proportion of participants was in the category with Grades 9-12 (40.5\%), with Grades 5-8 being least represented (27.3\%) (Table 3).

\section{Visual acuity}

A total of 326 learners underwent the eye examination; 271 (83.1\%; 95\% confidence interval [CI], 79.1-87.2) learners had unaided LogMAR VA of $<0.20$ in the right eye, and 268 (82.2\%; 95\% CI, 78.1-86.4) learners had normal LogMAR VA in the left eye. Fifty-five learners (16.9\%; 95\% CI, 12.8-20.9) had uncorrected LogMAR VA of $\geq 0.20$ in the right eye, and 57 learners (17.5\%; $95 \%$ CI, 13.4-21.6) had uncorrected LogMAR VA of $\geq 0.20$ in the left eye, as shown in Table 4 . One learner $(0.3 \%$; 95\% CI, 0.00-0.90) had uncorrected LogMAR VA of worse than 1.00 in the left eye. In total, 67 learners (20.6\%; 95\% CI, 16.2-24.9) had uncorrected LogMAR VAs of $<0.20$ in one or both eyes.

None of the learners presented wearing any corrective devices like spectacles or contact lenses. The prevalence of uncorrected LogMAR VA of 0.20 or worse in the better eye was found to be $20.6 \%$ (95\% CI, 16.2-24.9), presenting was $20.6 \%$ (95\% CI, $16.2-$ $24.9)$ and best corrected was $2.1 \%$ (95\% CI, 0.60-3.70).

\section{Prevalence of visual impairment}

Forty learners (12.3\%; 95\% CI, 8.70-15.80) had VI as per the WHO definition, with a presenting VA worse than 0.30 in one or both eyes (46). Thirty learners (9.2\%; 95\% CI, 6.1-12.3) had mild VI, eight $(2.5 \%$; $95 \%$ CI, $0.80-4.10)$ moderate and two $(0.6 \%$; $95 \%$ CI, $0.00-1.50)$ severe VI (Table 5). There was no statistically significant difference in the prevalence of VI between males and females $(p=1.000)$ or between age groups $(p=0.744)$. Seven learners $(2.1 \% ; 95 \%$ CI, $0.60-3.70)$ could not achieve VA of $\geq 0.30$ in one or both eyes after correction.

TABLE 2: Distribution of participants according to age.

\begin{tabular}{|c|c|c|c|c|c|c|}
\hline \multirow[t]{2}{*}{ Age group (years) } & \multicolumn{2}{|c|}{ Males } & \multicolumn{2}{|c|}{ Females } & \multicolumn{2}{|c|}{ Total } \\
\hline & $n$ & $\%$ & $n$ & $\%$ & $n$ & $\%$ \\
\hline $6-9$ & 41 & 12.6 & 37 & 11.3 & 78 & 23.9 \\
\hline $10-13$ & 47 & 14.4 & 46 & 14.1 & 93 & 28.5 \\
\hline 14 and older & 73 & 22.4 & 82 & 25.1 & 155 & 47.5 \\
\hline Total & 161 & 49.4 & 165 & 50.6 & 326 & 100.0 \\
\hline
\end{tabular}

n, number.

TABLE 3: Distribution of participants according to grade.

\begin{tabular}{|c|c|c|c|c|c|c|}
\hline \multirow[t]{2}{*}{ Grades } & \multicolumn{2}{|c|}{ Males } & \multicolumn{2}{|c|}{ Females } & \multicolumn{2}{|c|}{ Total } \\
\hline & $n$ & $\%$ & $n$ & $\%$ & $n$ & $\%$ \\
\hline $1-4$ & 57 & 17.5 & 48 & 14.7 & 105 & 32.3 \\
\hline $5-8$ & 44 & 13.5 & 45 & 13.8 & 89 & 27.3 \\
\hline 9-12 & 60 & 18.4 & 72 & 22.1 & 132 & 40.5 \\
\hline
\end{tabular}

The leading cause of VI was uncorrected RE at 80\% (95\% CI, 67.6-92.4), followed by amblyopia, corneal opacity or scar and cataract with findings of $10 \%$ (95\% CI, 0.70-19.3), 7.5\% (95\% CI, 0.00-15.7) and 2.5\% (95\% CI, 0.00-7.30).

\section{Refractive error}

The prevalence of $\mathrm{RE}$ is based on the cycloplegic autorefraction results of the 324 learners $(99.4 \%$ of the sample) who satisfied both criteria for full cycloplegia. Furthermore, the prevalence of RE was based on uncorrected LogMAR VA of 0.20 in one or both eyes, as was the case with 67 learners $(20.6 \%$; 95\% CI, 16.2-24.9).

The overall prevalence of RE for this study was 20.6\%, with a greater prevalence observed in the age group 14-18 years. There was no significant difference in the prevalence of RE between females and males $(p=0.325)$. Learners in Grades 9-12 $(n=31)$ had a higher prevalence $(46.3 \%$; 95\% CI, 34.3-58.2) than all other grades. Refractive error was evenly distributed amongst different schools, except in one school, where there was a prevalence of $68 \%$ (i.e. Nokomeetse Primary School).

The most prevalent type of RE was found to be myopia at $10.4 \%$ (95\% CI, 7.10-13.7), with a higher prevalence of myopia in males $(55.9 \%$; 95\% CI, 39.2-72.6) than females (44.1\%; 95\% CI, 27.4-60.8). It was also associated with an increase in age as indicated by Table 6 . The amount of myopia ranged from $-0.50 \mathrm{D}$ to $-18.50 \mathrm{D}$. The prevalence of hypermetropia was $(2.8 \%, 95 \% \mathrm{CI}, 1.00-4.50)$ of the overall sample. Hypermetropia ranged from $2.00 \mathrm{D}$ to $5.50 \mathrm{D}$; it was more prevalent at ages 6-9 and 14-18 years and was associated with females at $77.8 \%(95 \% \mathrm{CI}, 50.0-100)$ as compared to $22.2 \%$ (95\% CI 0.00-49.4) of males. Astigmatism ranged from $-0.75 \mathrm{D}$ to $-5.50 \mathrm{D}$ cylinder, and the prevalence in the sample was $7.4 \%(95 \% \mathrm{CI}, 4.5-10.2)$. A higher prevalence of astigmatism was observed in the 10-13-year age group, as highlighted in Table 6, but there was no significant difference in the prevalence of astigmatism between genders.

\section{Binocular motor function}

Heterotropia was found in four children (1.2\%). All four had exotropia when viewing a near target $(50 \mathrm{~cm})$, and three had exotropia when viewing a target at $4 \mathrm{~m}$. The magnitude of exotropia ranged from $1^{\circ}$ to $30^{\circ}$.

TABLE 4: Distribution of uncorrected visual acuity in logarithm of the minimum angle of resolution for right and left eyes.

\begin{tabular}{|c|c|c|c|c|c|c|}
\hline \multirow{2}{*}{$\begin{array}{l}\text { Range of } \\
\text { UVA in LogMAR } \\
\text { (Snellen equivalent) }\end{array}$} & \multicolumn{3}{|c|}{ Right eye } & \multicolumn{3}{|c|}{ Left eye } \\
\hline & $n$ & $\%$ & $95 \% \mathrm{Cl}$ & $n$ & $\%$ & $95 \% \mathrm{Cl}$ \\
\hline $0.00-0.18(6 / 6->6 / 9)$ & 271 & 83.1 & $79.1-87.2$ & 268 & 82.2 & $78.1-86.4$ \\
\hline $0.20-0.30(6 / 9-6 / 12)$ & 25 & 7.7 & $4.8-10.6$ & 30 & 9.2 & $6.1-12.3$ \\
\hline $0.32-0.50(<6 / 12-6 / 19)$ & 19 & 5.8 & $3.3-8.4$ & 19 & 5.8 & $3.3-8.4$ \\
\hline $0.52-1.0(<6 / 19-6 / 60)$ & 11 & 3.4 & $1.4-5.3$ & 8 & 2.5 & $0.8-4.1$ \\
\hline$>1.00(<6 / 60)$ & 0 & 0.0 & 0.00 & 1 & 0.3 & $0.00-0.9$ \\
\hline
\end{tabular}

UVA, uncorrected refractive error; LogMAR, logarithm of the minimum angle of resolution; $n$, number; $\mathrm{Cl}$, confidence interval. 
TABLE 5: Prevalence of visual impairment according to gender, age and grade.

\begin{tabular}{|c|c|c|c|c|c|c|c|c|}
\hline \multirow[t]{3}{*}{ Variable } & \multicolumn{8}{|c|}{ Types of visual impairments } \\
\hline & \multicolumn{2}{|c|}{ Mild Vl† } & \multicolumn{2}{|c|}{ Moderate VI\$ } & \multicolumn{2}{|c|}{ Severe VI§ } & \multicolumn{2}{|c|}{ Total } \\
\hline & $n$ & $\%$ & $n$ & $\%$ & $n$ & $\%$ & $n$ & $\%$ \\
\hline \multicolumn{9}{|l|}{ Gender } \\
\hline Male & 14 & 4.3 & 4 & 1.2 & 2 & 0.6 & 20 & 6.13 \\
\hline Female & 16 & 4.9 & 4 & 1.2 & 0 & 0.0 & 20 & 6.13 \\
\hline \multicolumn{9}{|c|}{ Age group (years) } \\
\hline $6-9$ & 7 & 2.1 & 1 & 0.3 & 0 & 0.0 & 8 & 2.5 \\
\hline $10-13$ & 5 & 1.5 & 2 & 0.6 & 1 & 0.3 & 8 & 2.5 \\
\hline $14+$ & 18 & 5.5 & 5 & 1.5 & 1 & 0.3 & 24 & 7.3 \\
\hline \multicolumn{9}{|l|}{ Grades } \\
\hline $1-4$ & 9 & 2.8 & 2 & 0.6 & 0 & 0.0 & 11 & 3.4 \\
\hline $5-8$ & 7 & 2.1 & 1 & 0.3 & 1 & 0.3 & 9 & 2.8 \\
\hline 9-12 & 14 & 4.3 & 5 & 1.5 & 1 & 0.3 & 20 & 6.13 \\
\hline
\end{tabular}

$n$, number; $\mathrm{VI}$, visual impairment; $\mathrm{V} / \mathrm{A}$, visual acuity.

$\dagger, \mathrm{V} / \mathrm{A}$ of worse than 0.32 , but better than 0.50

$\pm \mathrm{V} / \mathrm{A}$ of worse than 0.50 , but better than 1.00

$\S, \mathrm{V} / \mathrm{A}$ or worse than 1.00

\section{Anterior segment examination}

No learner was found to have any eye lid abnormalities, and in all learners, the pupils were equally round and reactive to light and accommodation. Eleven learners (3.4\%) presented with vernal conjunctivitis, and corneal scars or opacities were observed in three learners $(1 \%)$.

\section{Posterior segment examination}

Out of the total of 326 learners, one learner $(0.3 \%)$ presented with a cataract in the left eye, and therefore, the vitreous and fundus could not be examined. The remainder (99.7\%) had clear and normal media and fundi.

\section{Referral system}

A total of 67 learners $(20.86 \%)$ were referred to eye care practitioners of their choice for a full refraction and prescription of spectacles, if necessary. Eleven learners who had vernal keratoconjunctivitis (VCK) were referred to eye hospitals for further management.

\section{Discussion}

The VI prevalence of $12.3 \%$ found in the greater Sekhukhune District of Limpopo Province was similar to the VI prevalence of $12.2 \%$ found in Vietnam, ${ }^{21}$ but it is higher than the reported $7.9 \%$ prevalence of a study performed amongst $10-18$ yearold school learners in Calabar, Nigeria. ${ }^{49}$ This prevalence value is lower than the prevalence of $29.4 \%$ reported from a study in Egypt (South Sinai), which had defined VI as a presenting VA of $\leq 6 / 9 .^{40}$ The reason for this difference in prevalence values might be the fact that these studies were performed in different locations and within different population groups.

The leading cause of VI in this study was RE that could be corrected with spectacles. These findings are comparable to those of another study done in South Africa with $63.6 \%$ of cases of VI being a result of RE. ${ }^{24}$ This means that most of these learners could be affected academically, socially and
TABLE 6: Prevalence of refractive error according to gender, age and grade.

\begin{tabular}{|c|c|c|c|c|c|c|}
\hline \multirow[t]{2}{*}{ Variable } & \multicolumn{2}{|c|}{$\begin{array}{l}\text { Prevalence of } \\
\text { myopia }\end{array}$} & \multicolumn{2}{|c|}{$\begin{array}{l}\text { Prevalence of } \\
\text { hypermetropia }\end{array}$} & \multicolumn{2}{|c|}{$\begin{array}{l}\text { Prevalence of } \\
\text { astigmatism }\end{array}$} \\
\hline & $n$ & $\%$ & $n$ & $\%$ & $n$ & $\%$ \\
\hline \multicolumn{7}{|l|}{ Gender } \\
\hline Male & 19 & 5.8 & 2 & 0.6 & 13 & 4.0 \\
\hline Female & 15 & 4.6 & 7 & 2.1 & 11 & 3.4 \\
\hline Total & 34 & 10.4 & 9 & 2.7 & 24 & 7.4 \\
\hline \multicolumn{7}{|c|}{ Age group (years) } \\
\hline $6-9$ & 0 & 0.0 & 4 & 1.2 & 6 & 1.8 \\
\hline $10-13$ & 6 & 1.8 & 1 & 0.3 & 12 & 3.7 \\
\hline $14-18$ & 28 & 8.6 & 4 & 1.2 & 6 & 1.8 \\
\hline Total & 34 & 10.4 & 9 & 2.7 & 24 & 7.4 \\
\hline \multicolumn{7}{|l|}{ Grades } \\
\hline $1-4$ & 1 & 0.3 & 5 & 1.5 & 11 & 3.4 \\
\hline $5-8$ & 9 & 2.8 & 1 & 0.3 & 9 & 2.8 \\
\hline $9-12$ & 24 & 7.4 & 3 & 0.9 & 4 & 1.2 \\
\hline Total & 34 & 10.4 & 9 & 2.7 & 24 & 7.4 \\
\hline
\end{tabular}

$n$, number.

psychologically by a condition that could be managed by a simple pair of spectacles. Moreover, if this condition is not managed, it could lead to more complicated conditions like amblyopia, which cannot be managed but leads to low vision and ultimately blindness. This indicates a serious need for school vision screening, as it will help with detection of RE and a further management plan. Moreover, there is a need for provision of spectacles at reasonable or low cost in order to cater for children. In most of the schools included in this research study, no vision screening had been performed. A possible reason for the lack of vision screening could be the inaccessibility of the location, as most of these schools are located in the hills and mountains, which poses a challenge and makes them difficult to reach.

In $7(2.1 \%)$ learners, vision could not be corrected with spectacles to LogMAR 0.30 or better. The prevalence of $2.1 \%$ was higher than that of the $0.32 \%$ prevalence reported by Naidoo et al. ${ }^{24}$ for a study performed in South Africa. A recent study conducted in Nigeria also found a lower prevalence of $1.3 \%,{ }^{32}$ possibly a result of the fact that they focused on urban children, whilst this study was conducted on rural schoolgoing children. Urban leaners have access to eye care services, 
unlike rural learners who generally do not have these services. Urban children therefore have earlier detection and management of RE, before it leads to VI. That is why in the Nigerian study, more than 20 learners presented wearing spectacles, contrary to this study.

There was equal distribution of VI between males and females. This was expected because during the time of recruiting subjects for this study, gender was taken into consideration. This is comparable to the study conducted in Aba, Nigeria. ${ }^{26}$ Visual impairment was associated with an increase in age, with highest prevalence seen in the age group $14-18$ years $(60 \%$; 95\% CI, 44.8-60.0). This is because there is an association between the progression of myopia and puberty. Puberty starts around the age of 10-16 years. ${ }^{50}$

Four learners had amblyopia in one or both eyes, which is $1.2 \%$ of the total population. Their ages were $6,11,15$ and 18 years, and perhaps it could have been prevented if these learners had had visual assessment earlier. However, even at this stage with an appropriate form of correction and visual therapy, vision might improve in these learners. The results of this study are comparable to those of a recent study done in South Africa by Wajuihian and Hansraj, ${ }^{18}$ which also found a value of $1 \%$. Three learners presented with corneal opacity or scar and one with cataract. Cataract is also one of the leading causes of avoidable blindness worldwide. This condition can be managed by surgery. In many circumstances, cataract remains unmanaged because of lack of vision screening, the high cost of surgery and the cataract surgery backlog in public hospitals.

The prevalence of RE amongst school-going children in the greater Sekhukhune District (Limpopo, South Africa) was $20.6 \%$, which was high as compared to two previous studies conducted in South Africa in 2003 and 2017 that found prevalence values of $14 \%{ }^{22}$ and $15 \%,{ }^{17}$ respectively, as indicated in Table 1. These two studies were done in KwaZuluNatal, a different location from this study. The 2003 study was done more than 16 years ago before the introduction of smartphones to children, while the 2017 study only considered older learners, aged 13-18-years. This study is comparable to the study conducted by $\mathrm{Pi}$ et al. ${ }^{6}$ in a Chinese population.

This again highlights the need for eye care services to schoolgoing children, particularly considering that in this study none of those learners presented with any form of corrective devices. The challenge that arises, though, is ensuring that the learners are able to access any required visual assistive device. Similar to this study, several studies reported a higher prevalence of $\mathrm{RE}$ than the expected range of $2 \%-10 \%$ reported by the WHO concerning the African continent. Some of those studies had prevalence values of $25.6 \%, 22.8 \%$ and $18.9 \%$ for Ghana, Egypt $^{51}$ and Rwanda, ${ }^{52}$ respectively. This suggests that some children with RE might be overlooked, especially those in the deep rural areas of developing countries.

Myopia was found to be the leading type of RE in the current study $(10.4 \%)$. Globally, the prevalence of myopia is $11.7 \%$, which is a little higher than the results in this study. ${ }^{5}$ Holden et al. ${ }^{53}$ estimate that by 2050 the prevalence of myopia will be at $34 \%$ globally. This is because of the factors associated with myopia, like increased near-work activities, low levels of outdoor activity and reduced light levels. However, the mechanisms surrounding the development and progression of this condition are not yet fully understood, as myopia seems to be multifactorial in nature..$^{54}$ Similar to our study, a myopia prevalence of $10.4 \%$ was observed in Malabo, Equatorial Guinea, in 2015. ${ }^{45}$ Furthermore, the highest prevalence of $16.2 \%$ was observed in Beni-Suef (Egypt). ${ }^{16}$ In other studies done in Ghana and Malawi, whilst myopia was also found to be the leading type of RE, lower prevalences of $3.7 \%{ }^{13}$ and $1.4 \%{ }^{44}$ respectively, were found in these areas.

In the study herein, a higher prevalence of myopia was observed in the older age group (14-18 years). A higher prevalence in older school-going children was also reported by Ezinne and Mashige ${ }^{34}$ in Anambra State, Nigeria.

As children are expected to have higher near-task demands at higher grades, this finding may be attributed to the axial elongation, and subsequently myopia development, associated with intensive near work..$^{55}$ Myopia was also more prevalent in males than females, which corresponds to the results in studies done by Parmar, ${ }^{30}$ Awan $^{31}$ and Ezinne. ${ }^{34}$ Observation of the practices and culture in this area indicates that boys are more engaged with TV and cell phone games as compared to girls, who do lot of outdoor activities like fetching wood and water for cooking after school. This could be linked to more boys becoming myopic as compared to girls. To the contrary, Ekpenyong et al. ${ }^{14}$ found a higher prevalence of myopia in girls. This might be a result of the fact that in their study they had more female $(53 \%)$ than male $(47 \%)$ participants. However, Atowa et al. ${ }^{26}$ and Wajuihian and Hansraj ${ }^{17}$ found no significant difference in the prevalence of myopia based on gender.

The prevalence of hypermetropia $(2.8 \%)$ was low in the greater Sekhukhune District. These results corroborate those of Soler et al., ${ }^{45}$ who also found a low prevalence of $3.1 \%$ in Malabo, Equatorial Guinea. In contrast, in another province in South Africa, Wajuihian and Hansraj ${ }^{17}$ found a $5 \%$ prevalence of hypermetropia, higher than that reported in other studies. This difference could be related to the different definition of hypermetropia; Wajuihian and Hansraj ${ }^{17}$ defined hypermetropia as a value of at least $+0.50 \mathrm{D}$, whilst in the current study, a higher value of at least $+2.00 \mathrm{D}$ applied. Hypermetropia was slightly more prevalent in the younger age groups than the older age group, which is in keeping with the theory that children are born with hypermetropia that decreases with an increase in age. ${ }^{56}$ Li Zhijian et al. ${ }^{27}$ reported a similar trend in Northern China. Moreover, hypermetropia was seen more amongst females than males, as also found by Hashemi et al. ${ }^{57}$ amongst Iranian school-going children. On the contrary, Kawuma and Mayeku ${ }^{58}$ found male hypermetropia to be more prevalent in Kampala District.

The prevalence of astigmatism was relatively high (7.4\%) in greater Sekhukhune. Naidoo et al. ${ }^{24}$ and Kumah et al. ${ }^{13}$ also 
found a higher prevalence of astigmatism, as was noted in Table 6. In contrast, comparatively lower prevalences of $0.1 \%$, $0.3 \%$ and $0.1 \%$ were found in Tanzania, ${ }^{42}$ Kenya $^{43}$ and Malawi, ${ }^{44}$ respectively. This difference in the findings might be a result of the ethnic and racial differences.

The heterotropia prevalence for this study was $1.2 \%$, comparable to the study conducted in South Africa by Naidoo et al. ${ }^{24}$ which found a value of $1.3 \%$. However, this funding is lower than the prevalence of $17.5 \%$ that was found amongst Nigerian children ${ }^{32}$ but higher than $0.03 \%$, which was found in South Darfur..$^{59}$ Vernal conjunctivitis was seen in $3.4 \%$ of the study population, which is relatively similar to the $3.6 \%$ found by Naidoo et al. $^{24}$ The presence of vernal conjunctivitis is most probably a result of the rural environmental in which the participants live. Sekhukhune District is very hot and dry. Cataract was observed in $0.3 \%$ of the population, which is lower than the prevalences of $2.3 \%$ and $4.2 \%$ found in South Africa ${ }^{24}$ and Ethiopia, ${ }^{15}$ respectively.

\section{Limitations}

This study only included learners from Makhuduthamaga Municipality to represent the entire area of greater Sekhukhune, which might have created a bias. The final sample had a higher participation rate from 14-18-year-old children, which may have skewed the results to be more representative of this age group.

\section{Conclusion}

This study contributes to the epidemiological database on VI and RE in children. The results of this study are useful for stakeholders in all sectors involved in child eye health. School health programmes and other programmes involved in vision screening can use this information to devise strategies to address the current challenge of RE and VI as the leading causes of blindness in Africa.

\section{Acknowledgements}

Mrs Xulu-Kasaba is acknowledged for paying all publishing costs.

\section{Competing interests}

The authors declare that they have no financial motives that could have influenced the writing of this article.

\section{Authors' contributions}

T.S.S.M., Z.N.Q.X.-K. and R.H. conceptualised the project and designed the methodology. T.S.S.M. drafted the initial manuscript. R.H. and Z.N.Q.X.-K. supervised the project, guided and reviewed drafts up to the final article.

\section{Funding information}

The University of KwaZulu-Natal (UKZN) College of Health Sciences partly funded the fieldwork.

\section{Data availability statement}

The data are available on request.

\section{Disclaimer}

The views expressed in this article are those of the authors and do not necessarily reflect the official policy of the University of KwaZulu-Natal.

\section{References}

1. World Health Organization (WHO). Priority eye diseases. Geneva: World Health Organization; 2018.

2. Sieving PA. Facts about refractive errors [homepage on the Internet]. National Eye Institute, n.d. [cited 2018 Nov 12]; p. 1-2. Available from: https://nei.nih.gov/ health/errors/errors

3. DeCarlo DK, Woo S, Woo GC. Patients with low vision. In: Benjamin WJ, editor. Borish's Clinical Refraction, Philadelphia; 2006

4. Rahi JS, Solebo AL, Cumberland PM. Uncorrected refractive error and education. BMJ. 2014 6:5991. https://doi.org/10.1136/bmj.g5991

5. Hashemi H, Fotouhi A, Yekta A, et al. Global and regional estimates of prevalence of refractive errors: Systematic review and meta-analysis. J Curr Ophthalmol. 2018;30(1):3-22. https://doi.org/10.1016/j.joco.2017.08.009

6. Pi $L H, C h e n ~ L, ~ L i u ~ Q$, et al. Prevalence of eye diseases and causes of visual impairment in school-aged children in Western China. J Eppidemiol. 2012;22(1):37-44. https://doi.org/10.2188/jea.JE20110063

7. Chatterjee S, Biswas D, Kumar J. ISSN (o): 2321-7251. Prevalence of refractive errors in school children in the urban population of Kolkata, India: A prospective study. Int J Res Health Sci. 2014;(4):1185-1187.

8. Aldebasi YH. Prevalence of correctable visual impairment in primary schoo children in Qassim Province, Saudi Arabia. J Optom. 2014;7(3):168-176. https:// doi.org/10.1016/j.optom.2014.02.001

9. Kim EC, Morgan IG, Kakizaki $H$, et al. Prevalence and risk factors for refractive errors: Korean National Health and Nutrition Examination Survey 2008-2011. PLoS One. 2013;8(11):e80361. https://doi.org/10.1371/journal.pone.0080361

10. Barria F, Conte F, Munoz S, et al. Prevalence of refractive error and spectacle coverage in schoolchildren in two urban areas of Chile. Pan Am J Public Health. 2018;42:1-8. https://doi.org/10.26633/RPSP.2018.61

11. Mayro EL, Hark LA, Shiuey E, et al. Prevalence of uncorrected refractive errors among school-age children in the School District of Philadelphia. J Am Assoc Pediatr Ophthalmol Strabismus. 2018;22(3):214.e2-217.e2. https://doi. org/10.1016/j.jaapos.2018.01.011

12. Gao Z, Meng N, Muecke J, et al. Refractive error in school children in an urban and rural setting in Cambodia. Ophthalmic Epidemiol. 2012;19(1):16-22. https://doi. org/10.3109/09286586.2011.632703

13. Kumah BD, Ebri A, Abdul-Kabir M, et al. Refractive error and visual impairment in private school children in Ghana. Optom Vis Sci. 2013;90(11):1456-1461. https:// doi.org/10.1097/OPX.0000000000000099

14. Ekpenyong BN, Naidoo K, Ahaiwe K, et al. Visual status and prevalence of eye disorders among school-age children in southern Nigeria. African Vis Eye Health 2017;76(1):1-6. https://doi.org/10.4102/aveh.v76i1.377

15. Mehari ZA, Yimer AW. Prevalence of refractive errors among schoolchildren in rural central Ethiopia. Clin Exp Optom. 2013;96(1):65-69. https://doi. org/10.1111/j.1444-0938.2012.00762.x

16. Arafa AEE-D, Ewis AAE, Mahran WM, et al. Prevalence and risk factors of refractive students in Beni-Suef, Egypt. J Public Health (Bangkok). 2018;27(1):1-5. https://doi.org/10.1007/s10389-018-0930-8

17. Wajuihian SO, Hansraj R. Refractive error in a sample of black high school children in South Africa. Optom Vis Sci. 2017;94(12):1145-1152. https://doi.org/10.1097/ OPX.0000000000001145

18. You QS, Wu LJ, Duan JL, et al. Prevalence of myopia in school children in greater Beijing: The Beijing childhood eye study. Acta Ophthalmol. 2014;92(5):e398e406. https://doi.org/10.1111/aos.12299

19. Wu JF, Bi HS, Wang SM, et al. Refractive error, visual acuity and causes of vision loss in children in Shandong, China. The Shandong children eye study. Barnes S, editor. PLoS One. 2013;8(12):e82763. https://doi.org/10.1371/journal.pone.0082763

20. Al Wadaani FA, Amin T, Ali A, et al. Prevalence and pattern of refractive errors among primary school children in Al Hassa, Saudi Arabia. Glob J Health Sci. 2012;5(1):125-134. https://doi.org/10.5539/gjhs.v5n1p125

21. Paudel $P$, Ramson $P$, Naduvilath $T$, et al. Prevalence of vision impairment and refractive error in school children in Ba Ria - Vung Tau province, Vietnam. Clin Experiment Ophthalmol. 2014;42(3):217-226. https://doi.org/10.1111/ceo.12273

22. Sewunet SA, Aredo KK, Gedefew M. Uncorrected refractive error and associated factors among primary school children in Debre Markos District, Northwest Ethiopia. BMC Ophthalmol. 2014;14(1):95. https://doi.org/10.1186/1471-2415-14-95

23. French AN, Morgan IG, Burlutsky G, et al. Prevalence and 5- to 6-year incidence and progression of Myopia and Hyperopia in Australian school children. Ophthalmology. 2013;120(7):1482-1491. https://doi.org/10.1016/j.ophtha.2012. 12.018

24. Naidoo KS, Raghunandan A, Mashige KP, et al. Refractive error and visual impairment in African children in South Africa. Investig Ophthalmol Vis Sci. 2003;44(9):3764. https://doi.org/10.1167/iovs.03-0283 
25. Caca I, Cingu AK, Sahin A, et al. Amblyopia and refractive errors among schoolaged children with low socioeconomic status in Southeastern Turkey. J Pediat Ophthalmol Strabismus. 2013;50(1):37-43. https://doi.org/10.3928/0191391320120804-02

26. Atowa UC, Munsamy AJ, Wajuihian SO. Prevalence and risk factors for myopia among school children in Aba, Nigeria. African Vis Eye Health. 2017;76(1):1-5. Available from: https://doi.org/10.4102/aveh.v76i1.369

27. Li Z, Xu K, Wu S, et al. Population-based survey of refractive error among schoolaged children in rural northern China: The Heilongjiang eye study. Clin Experiment Ophthalmol. 2014;42(4):379-384. https://doi.org/10.1111/ceo.12198

28. Wu PC, Tsai CL, Wu HL, et al. Outdoor activity during class recess reduces Myopia onset and progression in school children. Ophthalmology. 2013;120(5):10801085. https://doi.org/10.1016/j.ophtha.2012.11.009

29. Lim HT, Yoon JS, Hwang S-S, et al. Prevalence and associated sociodemographic factors of myopia in Korean children: The 2005 third Korea National Health and Nutrition Examination Survey (KNHANES III). Jpn J Ophthalmol. 2012;56(1):76-81. https://doi.org/10.1007/s10384-011-0090-7

30. Parmar A, Kartha G, Baria M. A study on the prevalence of refractive errors among school children of 10-16 years in Surendranagar district, Gujarat. Int J Community Med Public Health. 2017;4(9):3376. https://doi.org/10.18203/2394-6040.ijcmph 20173848

31. Awan AR, Jamshed J, Khan MM, et al. Prevalence and causes of visual impairment and blindness among school children in Muzaffarabad, Pakistan. Int J Sci Rep. 2018;4(4):93. https://doi/org/10.18203/issn.2454-2156. IntJSciRep20181393

32. Ezinne NE, Mashige KP. Refractive error and visual impairment in primary schoo children in Onitsha, Anambra State, Nigeria. African Vis Eye Health. 2018;77(1): 1-8. https://doi.org/10.4102/aveh.v77i1.455

33. Kedir J, Girma A. Prevalence of refractive error and visual impairment among rural school-age children of Goro district, Gurage zone, Ethiopia. Ethiop J Health Sci. 2014;24(4):353. https://doi.org/10.4314/ejhs.v24i4.11

34. Resnikoff S. Assessment of the prevalence of visual impairment attributable to refractive error or other causes in school children. Protocol and manual. Geneva: World Health Organization; 2007.

35. Pascolini D, Mariotti SP. Global estimates of visual impairment: 2010. Br J Ophthalmol. 2012;96(5):614-618. https://doi.org/10.1136/bjophthalmol-2011-300539.

36. Barria $F$, Conte $F$, Muñoz $S$, et al. Prevalence of refractive error and spectacle coverage in school children in two urban areas of Chile. Rev Panam Salud Pública. 2018;42:1-8. https://doi.org/10.26633/RPSP.2018.61

37. Casson RJ, Kahawita S, Kong A, et al. Exceptionally low prevalence of refractive error and visual impairment in school children from Lao People's Democratic Republic. Ophthalmology. 2012;119(10):2021-2027. https:doi.org/10.1016/j ophtha.2012.03.049

38. Kumar $P$, Pore $P$, Dixit $A K$, et al. Prevalence and demographic distribution of refractory error in school children of Pune, India. Int J Res Health Sci. 2014;(1): 58-67.

39. Naipal S, Rampersad N. A review of visual impairment. African Vis Eye Health. 2018;77(1):1-4. https://doi.org/10.4102/aveh.v77i1.393

40. Yamamah GAN, Talaat Abdel Alim AA, Mostafa YSED, et al. Prevalence of visua impairment and refractive errors in children of South Sinai, Egypt. Ophthalmic Epidemiol. 2015;22(4):246-252. https://doi.org/10.3109/09286586.2015.1056811

41. Ovenseri-Ogbomo GO, Omuemu VO. Prevalence of refractive error among schoo children in the Cape Coast Municipality, Ghana. Clin Optom. 2010;2:59-66. https://doi.org/10.2147/OPTO.S10583

42. Wedner SH, Ross DA, Balira R, et al. Prevalence of eye diseases in primary school children in a rural area of Tanzania. Br J Ophthalmol [serial online]. 2000 [cited 2018 Oct 12];84(11):1291-1297. Available from: http://bjo.bmj.com/
43. Muma MK, Kimani K, Wanyoike MK, et al. Prevalence of refractive errors among primary school pupils in Kilungu division of Makueni district, Kenya. Med I Zambia [serial online]. 2009 [cited 2018 Oct 12];36(4):165-170. Available from: http:// www.ajol.info/index.php/mjz/article/view/76373\%

44. Tinkhani Msiska $V$, Of Nairobi. Magnitude and pattern of significant refractive errors among primary school children in Ntcheu and Lilongwe districts in Malawi [homepage on the Internet]. [cited 2018 Oct 12]. Available from: http://erepository. uonbi.ac.ke/bitstream/handle/11295/25194/Msiska Magnitude and pattern of uonbi.ac.ke/bitstream/handle/11295/25194/Msiska_Magnitude and pattern
significant refractive errors among primary school children.pdf?sequence $=3$

45. Soler M, Anera RG, Castro JJ, et al. Prevalence of refractive errors in children in Equatorial Guinea. Optom Vis Sci. 2015 [cited 2018 Jun 19];92(1):53-58. https://doi.org/10.1097/OPX.0000000000000448

46. Final IDP/Budget Review 2017-2018. By the executive mayor: Councillor Keamotseng Stanley Ramaila. Polokwane [homepage on the Internet]. [cited 2018 Oct 23]. Available from: http://www.sekhukhunedistrict.gov.za/sdm-admin/ Oct 23]. Available from: http://www.se
documents/IDPFinal2017-2018(2)(2).pdf

47. Lehohla AP, Statistics South Africa. The state of basic service delivery in South Africa: In-depth analysis of the Community Survey 2016. Statistics South Africa. Pretoria: Statistics South Africa; 2016.

48. Murdoch IE, Allstair Laidlaw DH, Rosser DA, et al. Reduced logMAR visual acuity test chart. London: United States Patent; 2000

49. Ebri AE, Govender P, Naidoo KS. Prevalence of vision impairment and refractive error in school learners in Calabar, Nigeria. African Vis Eye Health. 2019;78(1):1-8. https://doi.org/10.4102/aveh.v78i1.487

50. Puberty definition, stages, duration, signs for boys \& girls [homepage on the Internet]. [cited 2019 Dec 11]. Available from: https://www.medicinenet.com/ puberty/article.htm

51. Opubiri I, Pedro-Egbe C. Screening for refractive error among primary school children in Bayelsa state, Nigeria. Pan Afr Med J. 2013;14(1):74. https://doi. org/10.11604/pamj.2013.14.74.1345

52. Semanyenzi S, Karimurio J, Nzayirambano M. Prevalence and pattern of refractive errors in high schools of Nyarugenge district. East African J Ophthalmol [serial online]. 2015 [cited 2020 Jun 28];13. Available from: https://www.google.com/ search?rlz=1C1CHBD

53. Holden BA, Fricke TR, Wilson DA, et al. Global prevalence of myopia and high myopia and temporal trends from 2000 through 2050. Ophthalmology. 2016;123(5):1036-1042. https://doi.org/10.1016/j.ophtha.2016.01.006

54. Wolffsohn JS, Calossi A, Cho P, et al. Global trends in myopia management attitudes and strategies in clinical practice. Cont Lens Anterior Eye. 2016 Apr 1 39(2):106-116. https://doi.org/10.1016/j.clae.2016.02.005

55. Lee YY, Lo CT, Sheu SJ, et al. What factors are associated with myopia in young adults? A survey study in Taiwan military conscripts. Investig Ophthalmol Vis Sci. 2013 Feb;54(2):1026-1033. https://doi.org/10.1167/iovs.12-10480

56. Gupta N. Refractive error \& childhood visual impairment. Adv Ophthalmol Vis Syst. 2016 Oct 14;5(1)1-7. https://doi.org/10.15406/aovs.2016.05.00146

57. Hashemi H, Yekta A, Jafarzadehpur E, et al. High prevalence of refractive errors in 7 year old children in Iran. Iran J Public Health [serial online]. 2016 Feb [cited 2018 Jun 19];45(2):194-202. Available from: http://www.ncbi.nlm.nih.gov/pubmed/27114984

58. Kawuma M, Mayeku R. A survey of the prevalence of refractive errors among children in lower primary schools in Kampala district. Afr Health Sci [serial online]. 2002 Aug [cited 2019 Feb 6];2(2):69-72. Available from: http://www.ncbi.nlm. nih.gov/pubmed/12789105

59. Alrasheed SH, Naidoo KS, Clarke-Farr PC. Prevalence of visual impairment and refractive error in school-aged children in South Darfur State of Sudan. African Vis Eye Health. 2016;75(1). https://doi.org/10.4102/aveh.v75i1.355 